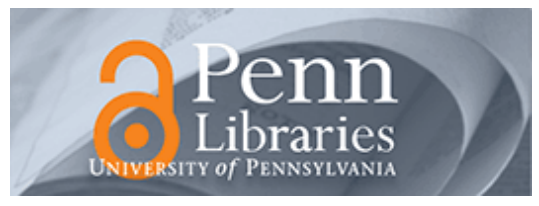

University of Pennsylvania ScholarlyCommons

$4-1-2002$

\title{
Struggling Toward Culturally Relevant Pedagogy in the Latino Diaspora
}

Stanton Wortham

University of Pennsylvania, stanton.wortham@bc.edu

Margaret Contreras

Kent's Hill School

Follow this and additional works at: https://repository.upenn.edu/gse_pubs

\section{Recommended Citation}

Wortham, S., \& Contreras, M. (2002). Struggling Toward Culturally Relevant Pedagogy in the Latino

Diaspora. Retrieved from https://repository.upenn.edu/gse_pubs/88

This is an electronic version of an article published in Journal of Latinos and Education, Volume 1, Issue 2, 2002, pages 133-144.. Journal of Latinos and Education is available online at: http://www.informaworld.com/

This paper is posted at ScholarlyCommons. https://repository.upenn.edu/gse_pubs/88

For more information, please contact repository@pobox.upenn.edu. 


\title{
Struggling Toward Culturally Relevant Pedagogy in the Latino Diaspora
}

\author{
Abstract \\ Increasing numbers of Latinos are settling in parts of the US where few Latinos have lived before. Many \\ of these diaspora Latinos are school-age children who do not yet speak English fluently. Although rural US \\ educators often work hard to serve Latino diaspora schoolchildren, most rural schools do not provide \\ enough support. This article describes the successes and failures of one paraprofessional working in the \\ Latino diaspora. By describing her strategies to make school more culturally familiar, as well as the \\ reactions Latino students and Anglo educators had to her efforts, the article illustrates both the potential \\ and the difficulty of culturally relevant pedagogy in the Latino diaspora.
}

\section{Keywords}

latino diaspora, culturally relevant pedagogy, bilingual education, paraprofessionals, rural education, spatiotemporal fluidity

\section{Comments}

This is an electronic version of an article published in Journal of Latinos and Education, Volume 1, Issue 2, 2002, pages 133-144.. Journal of Latinos and Education is available online at:

http://www.informaworld.com/ 
Struggling toward Culturally Relevant Pedagogy in the Latino Diaspora

\author{
Stanton Wortham \\ University of Pennsylvania \\ Graduate School of Education \\ 3700 Walnut Street \\ Philadelphia, PA 19104-6216 \\ (215) 898-6307 \\ FAX (215) 898-4399 \\ stantonw@gse.upenn.edu
}

\author{
Margaret Contreras \\ Kent's Hill School
}




\begin{abstract}
Increasing numbers of Latinos are settling in parts of the US where few Latinos have lived before. Many of these diaspora Latinos are school-age children who do not yet speak English fluently. Although rural US educators often work hard to serve Latino diaspora schoolchildren, most rural schools do not provide enough support. This article describes the successes and failures of one paraprofessional working in the Latino diaspora. By describing her strategies to make school more culturally familiar, as well as the reactions Latino students and Anglo educators had to her efforts, the article illustrates both the potential and the difficulty of culturally relevant pedagogy in the Latino diaspora.
\end{abstract}

Key words: Latino diaspora, culturally relevant pedagogy, bilingual education, paraprofessionals, rural education, spatiotemporal fluidity 
Freeman (1996) argues that, to be successful, bilingual education must be supported at several levels of the educational system — by policymakers, by the community, by administrators and teachers and by students. The rural New England town described in this article had some dedicated bilingual educators, many good students and sufficient funds for bilingual education. But because they lacked support from other elements of the system, many Latino children did not do as well as they could have. This article describes one bilingual educator's innovative attempt to develop culturally relevant pedagogy for her Latino students in this context.

\section{Margaret's ESL room}

Havertown High $^{1}$ is in a small rural New England town far from any sizable Latino community. About 200 Latinos, mostly from Mexico or Southern Texas, live in Havertown. (Only 1\% of US Latinos lived in the Northeast in the mid-1990s, where they comprised 0.3\% of the total population, but small diaspora communities like the one in Havertown are becoming increasingly common). Virtually all of the adults have come to work at a local meat processing plant. Turnover is very high, as families regularly leave town for other jobs or to return south. At any given time, about 50 Latino children are enrolled in the local schools (about $2 \%$ of the total school population). Margaret Contreras worked at the high school for 3 years as a bilingual paraprofessional, where she designed and staffed an ESL room for the Latino students. All the Latino students in Havertown schools attend mainstream classes, but many are pulled out of one or two classes a day in order to work in the ESL room in their particular school. Each ESL room is staffed by a bilingual paraprofessional, and certified ESL teachers come to the rooms to offer formal classes for "limited English proficient" students. For logistical reasons, however, the 
certified teachers rarely used Margaret's room, so she made it available to all Latino students at the high school. The first author, together with two research assistants, observed Margaret's ESL room daily for two months and interviewed teachers and students, as part of a two year ethnographic study of the Havertown Latino community.

Latino adolescents have mixed feelings about life in Havertown. On arrival they usually suffer culture shock at being transplanted into a community so devoid of Latinos. Margaret spent many hours with new students-often in tears-who refused even to leave the ESL room for fear of the unfamiliar, totally Anglo world of the school. The adolescents miss their Spanish-speaking friends, and Spanish language radio, although many families do have satellite dishes and watch the Spanish-language cable network Univisión. Due to the lack of friends, relatives and familiar activities they often find rural American life sterile and boring. The transience of Latino families also takes a toll. As reported by Stull, Broadway, and Erickson (1992), the turnover of workers in this sort of meatpacking job can be 6-8\% a month. Turnover among Havertown Latinos approaches this at times. Even children from families resident for several years often speculate that they will be leaving soon, and this expectation disrupts their commitments to school and friends.

On the other hand, many adolescents and their parents appreciate the quality of the schools-which they consider far better than those in southern Texas or rural Mexico. Some parents remain at extremely difficult jobs so that their children can finish school in Havertown. Many adolescents and their parents also value the lack of drugs and gang violence. Students report that they feel safe in Havertown, and parents worry less about the bad influences their children might fall under. The primary reason for these Latinos' presence in Havertown, however, is work. 
As described comprehensively by Griffith and Kissam (1995), the employment prospects of many agricultural workers based in southern Texas have become less secure in recent years. These workers now value a steady job above all else, and they find that in Havertown. The jobs are exhausting, often dirty, and pay the minimum wage. But workers get steady work and ample overtime year-round, and there is no shortage of new workers.

Finding Margaret Contreras' ESL room at Havertown High can be a challenge. You must go through the cafeteria and almost out the back door of the school, then enter the self-contained special education room for seriously disabled students. Through this room, past the eager stares of the disabled students, you will find a small room that must have been designed as a large storage closet (measuring about 12 feet by 9 feet). As you enter, you will see Margaret's small desk and chair immediately on your right. On the far wall are a filing cabinet, a desk with a computer, a map of the world and many Spanish-language posters. Compressed against the two side walls are two or three other desks and chairs, one housing a combination TV-VCR, a bookcase filled with Spanish-language books and books on bilingual education, plus students' work. A prominent portion of the right hand wall contains a gallery of hand-drawn pictures-each containing the nickname of a male Latino student. One says "El Tomate" in stylized letters and has a picture of a humanoid tomato that is supposed to resemble Paco the ninth grader. Margaret refers to this art work as "legal graffiti." The boys take pride in their pictures, and they consider it a mark of friendship to be given a nickname and enshrined on the wall.

If you visit Margaret's room in the morning, and if you are a mainstream Anglo, this small space will contain a dizzying amount of activity. Margaret sits at her desk, filling out forms and intermittently answering questions from the three students in the room. Jesús Villalobos and his 
friend Paco Moreno have been released from their ninth grade math class, which is at the moment taking a test. They are doing worksheets that they must finish before taking the test themselves. They alternate between Spanish and English, and between a conversation about a recent fight and their math homework. Jesús occasionally turns to the back wall and teases Teresa Fuentes, who is sitting behind him writing a paper on the computer. She sometimes teases back, but mostly she ignores him. One of the few African American students in the school enters the room, greets Margaret, and then remarks that no one saved a chair for him. He borrows one from the special education room, sits down beside Teresa, and proceeds to discuss her paper. At this point we have four students, one teacher, one ethnographer, two or three conversations and three different types of schoolwork going on in about 100 square feet.

On this day, Margaret had promised Jesús the opportunity to watch an educational video on the ancient Maya. Later in the period they turn on the VCR. Margaret continues with her paperwork, and Teresa continues with her paper, but both apparently attend to their work and the video simultaneously. Even more remarkable to the Anglo ethnographer (the first author), when he and Margaret begin a conversation in the corner the students manage to attend to that too. Teresa chimes in at exactly the right moment to contribute to the conversation, while still making progress on her paper and apparently learning something about the Maya. Toward the end of the movie other activities do stop for a few minutes, after Jesús remarks about one of the Mayan Indians that "his lips are like mine." Margaret uses this comment to start a discussion of "ethnic" appearance and its consequences, which becomes a discussion about how some Latino males have been getting stopped by local police.

In describing her classroom, Margaret often refers to herself as a "proud mother" and to the 
students as "my students." Her first goal was to gain the students' confidence, such that they knew she cared about them regardless of how they behaved. And the students do treat her in many ways like a mother. Jesús, whose own mother is in Mexico several months out of the year, brings Margaret presents and is particularly affectionate on Mothers' Day. Other students confide in Margaret, sharing secrets that they tell no other adult.

Margaret's maternal role is only one way in which her ESL room resembles a Latino home. Latino families are particularly close and highly value mutual support (Rothenberg, 1995;

Suárez-Orozco \& Suárez-Orozco, 1995; Valdés, 1996). Margaret has managed to establish a quasi-familial support group among most of the Latino students at the high school. By her third year in Havertown, when we did our ethnographic observations, most Latino students were interested in each others' lives and were willing to support each other academically and personally. More than half the Latino students in the high school would regularly gather in the ESL room during home-room period, in the fifteen minutes before school, to chat or help each other finish homework. Once a newcomer from Mexico, a young woman named Carmen who knew little English, dove right in and helped another Latino with his English-language science homework when she recognized the concepts from her schooling in Mexico. Carmen also spearheaded a project to include the children of a Oaxacan family who had until then been isolated in the school and community. These children spoke Spanish as a second language, after their indigenous language. Carmen boosted their self-confidence by telling them how Oaxacan artists had influenced Mexican art in an important way, and thus she managed to bring them more into the Latino group at Havertown High.

So Margaret's ESL room resembled a Latino family in at least three central ways. First, 
Margaret herself was maternal. She had high standards, but she cared for her students. Second, she encouraged students to be close to one another. In her room other students were not seen as competition or as distractions, but as resources to help others both succeed academically and develop pride in their home cultures. Third, Margaret allowed more fluid spatiotemporal boundaries around activities. Students often participated in more than one activity, in the same place and at the same time. This third characteristic is perhaps the most striking, because of the contrast between the extreme spatiotemporal compartmentalization of activities in a typical school and the fluidity of Margaret's ESL room.

\section{Spatiotemporal fluidity}

Based on her own experiences in Colombia, and with her Colombian husband and his family, ${ }^{2}$ Margaret had noticed more fluid spatiotemporal boundaries around activities in many Latino homes. There people do not focus on one activity at a time, but instead participate in several activities simultaneously. Margaret decided to make her ESL room more culturally relevant, by implementing this more fluid organization of activities. In doing so, she was implementing an uncommon type of culturally relevant pedagogy. She went beyond curriculum materials that draw on Latino cultures, and beyond the use of Spanish, to incorporate a culturally familiar way of organizing time, space and student participation. She was thus following a more "ecological" view of education and development, in which teachers go beyond content and language and also recognize less explicit aspects of minority students' cultural practices (Azmitia, Cooper, García \& Dunbar, 1996; Irvine, 1990; Rogoff, 1991).

Ethnographic work by the first author showed that Margaret's observations about 
spatiotemporal fluidity were accurate for the Havertown Latino community itself. A typical Anglo is overwhelmed by the level of activity in the Havertown Latino homes. The entire extended family, plus visitors, generally occupy the central area of the house-usually the kitchen and living room. Many activities often go on simultaneously, and in the same place: the TV is on; children are doing homework; more than one conversation is occurring, in person or on the phone; people transact business activities (selling things to visitors, filling out tax forms, etc.); some of the women are cooking; music is playing; neighbors are dropping by to borrow something or to chat; and family members are coming and going on various errands. Most amazing to the Anglo observer, people seem able to attend to several of these activities at once. While making progress on their homework or their tax forms, people chime in at the right moment with some comment for the ongoing conversation. There is generally a feeling of warm togetherness in such a scene, which is readily extended to guests. Havertown Latinos report that they like this arrangement in the home, because it allows them to communicate and help each other with the various tasks, and because it makes them feel connected to the group. One adolescent was horrified when asked why he didn't do homework alone in his room. He would feel alone and uncomfortable there, he said, and he would also be cut off from others' help.

Other ethnographic work on Latinos has described a similar pattern of spatiotemporal fluidity. Vélez-Ibáñez (1993; 1996) calls it the "simultaneity" of activities in time and space. He reports that spatiotemporal boundaries between activities are generally more fluid among Latinos than among Anglos. Some other researchers refer to this pattern in passing, (e.g., Vásquez, Pease-Alvarez, and Shannon, 1994; Gallimore and Goldenberg, 1993). Rogoff, Mistry, Göncü and Mosier (1993) provide an extensive and systematic description of simultaneous participation 
in multiple activities. They compare typical household organization and child-rearing practices among rural Indian, rural Guatemalan Mayan, middle class Turkish and middle class US families. The two middle class settings involve much more segregation of activities than the two rural, working class settings. In the rural homes, many more activities go on at once-from adult work to caregiving to socializing. And rural adults and children, especially the Guatemalan Mayans, often attend simultaneously to more than one activity, with each "uninterrupted by the other, with each line of attention maintained as smoothly as if there were no other focus" (Rogoff, Mistry, Göncü \& Mosier, 1993:50).

No Havertown Latinos are Guatemalan Mayan, although there are a few Guatemalans who have some indigenous ancestry. But we seem to be observing in Havertown a similar pattern of multiple activities and simultaneous attention to the one Rogoff, Mistry, Göncü and Mosier observed in Guatemala (and to some extent in rural India). This spatiotemporal fluidity most likely occurs among Mexican and Central American rural working classes in particular, not among Latinos of all social classes. Rothenberg (1995) describes substantial differences between rural and urban Mexicans, and notes that the often-cramped quarters of the rural working classes in Mexico often force several activities into one space. (Note, however, that Vélez-Ibáñez (1993) suspects middle-class Mexican households also have more fluid spatiotemporal boundaries than Anglo ones, so this pattern is likely culturally as well as economically distributed). It is also important to note that Latinos do of course have some spatial and temporal differentiation in their activities. More fluid boundaries also do not mean that Latinos tolerate constant interruptions. We claim merely that the spatial and temporal boundaries between activities are more fluid among many rural, working class Latinos than among middle class US Anglos. 
Mainstream Anglo homes often have relatively firm spatial and temporal boundaries around activities, with an expectation that people will focus on one activity at a time: children often do homework separately in their rooms, until they are finished, and if they need help an adult goes to their room; people watch TV in the living room, and the TV will often go off when dinner or another activity commences; parents pay bills at a desk, in an office or study, etc. More research would be required to document the extent of this difference among various groups, but a difference in degree of spatiotemporal fluidity clearly exists between mainstream Anglos and the less Americanized working class Latino families in Havertown.

As a central component of her culturally relevant pedagogy, Margaret organized her ESL room in a more Latino way with respect to spatiotemporal fluidity. Most often she and the students participated in more than one activity simultaneously. Students could enter and leave the room at will, without regard for passes. There was deliberately no clock. While in the room students were expected to work, but they were allowed to wander off-topic for a while before returning to their task. The next section reports that, while Latino students appreciated Margaret's culturally relevant pedagogy, Anglos often misunderstood it. Margaret successfully convinced some Anglos that fluid boundaries do not mean lack of substance-but just a different organization of it. Most Anglo school personnel, however, were not convinced.

Results of Margaret's culturally relevant pedagogy

Margaret succeeded in creating a Latino haven at Havertown High. One of our research assistants, who was raised in a Mexican family in Texas (and was feeling homesick while away at college), felt so at home in Margaret's room that she spent a hundred hours more than we had 
originally planned doing research. She described the ESL room as a "home away from home." The Latino students also appreciated the warm communal feeling of Margaret's room. By Margaret's third year more than half the Latino students at the high school could be found there every morning at $8 \mathrm{AM}$, and they often went out of their way to attend these gatherings. On one morning Paco arrived at this gathering rather disheveled and apparently exhausted. He reported that Jesús would not make it to school that day, because they had been out playing pool until 2 AM the night before. Someone asked him: "So what are you doing here." He replied, apparently without irony: "Because I wanted to be here with Mrs. Contreras."

Most Anglo school staff, however, did not share the Latino students' appreciation of Margaret's work. Some of them complained that in her quasi-maternal closeness with the Latino students was "not professional." They meant that she inappropriately blurred the boundaries between school and home. A professional, according to other school staff, maintains distance from students, both in order to maintain authority as a representative of the institution and to avoid possible legal liability. Although this attitude may have merit, the negative reaction to Margaret's innovations revealed a conflict of values that undermined Margaret's efforts.

Because of its more fluid spatiotemporal activity boundaries, many Anglo school staff found Margaret's ESL room overwhelming. With a few exceptions, most school staff interpreted the multiple activities and fluid boundaries in Margaret's room as evidence of sloppiness. As they conceived it, Margaret might be doing successful "mentoring," and perhaps occasional "tutoring," but she did not do "instruction." Mere tutoring, as they conceived it, could be done in the midst of other activities, but academic instruction cannot coexist with such distractions. From this perspective, students in Margaret's room seemed to be "hanging around," straying off task, and 
staff feared that "not much gets done there." (Many staff also did not like Margaret's disdain for hall passes). When asked by the first author to speculate about why Margaret's room operated the way it did, few staff mentioned cultural factors. Most attributed it to Margaret's personality, claiming that she was too "social" a person. The one differing opinion came from a second-generation Italian American teacher, who said that his cultural heritage made him feel at home in Margaret's room.

So Margaret and the Anglo school staff interpreted her ESL room differently. Margaret saw it as culturally relevant pedagogy. Most Anglos saw it as chaotic and unprofessional. This conflict had both practical and theoretical implications. Practically, Margaret managed to run the ESL room as she wanted for three years, but she then decided to leave Havertown High. Theoretically, the conflict between Margaret and the school illustrates how culturally relevant pedagogues can face a hard choice between academic success and instilling pride in students' home cultures. Anglo school staff, although perhaps less well-informed about Latino cultures than they might have been, had a reasonable argument: given the way US schools are organized-with individual academic achievement the primary goal (not community-building), with standardized curricula and assessments, with compartmentalized academic activities-Margaret's approach might not have been the best preparation for US school success.

We can treat this as an empirical question: did Margaret's culturally relevant pedagogy help Latino students both succeed in school and develop pride in their home cultures, or did it impede their academic performance? Without doubt, her approach built a Latino community and developed students' pride in being Latino. By Margaret's last year the room had become a haven for most of the Latino students. Even those fluent in English and at the top of their class came to 
the room-to chat, to do their work, and to help others. One academically successful girl, who had sworn only a year earlier never to speak Spanish again, was willingly translating passages and tutoring other students in Spanish. Many students opened up enough to discuss sensitive topics like boyfriends and pregnancy with Margaret. The students also came to care for each other. Whenever someone was in trouble, others were willing to help. So Margaret built community and provided a culturally familiar space within the school.

This in itself had some positive effects on Latino students' academic performance: formerly disruptive students were less so; students skipped school less often; and students would attempt assignments in Margaret's room that they would not have bothered with otherwise. Nonetheless, Margaret's efforts did not substantially improve Latino students' academic performance. Many Havertown Latino adolescents face the bind described by Suárez-Orozco and Suárez-Orozco (1995) and others: they are caught between the traditional Mexican values of their parents and mainstream US values. For complicated reasons, sketched in Wortham (2001), the Latina and Latino adolescents in Havertown adopt different adaptive strategies when faced with this conflict. Most Latinas behave like Ogbu's (1987) "voluntary" or "immigrant" minorities. While in school they adopt the school's values and work hard on academic tasks. At home they think of themselves as Mexican or Mexican American and share many of their parents' values. Most Latino male adolescents, however, behave more like Ogbu's "involuntary" or "caste" minorities. They do not accommodate to the school's expectations, because they do not want to “act white.” They expect to work in manufacturing, like their fathers, and they do not see school success as necessary.

This gender difference in attitudes toward school pre-dated Margaret's arrival, and it has 
lasted beyond her time in Havertown. In order to examine the impact of her culturally relevant pedagogy on the Latino students, then, we need to look at the two genders separately. The adolescent girls who were doing well in school before Margaret arrived continued to do well academically during her three years. Margaret was able to give personal attention to students, and this probably helped some Latinas make it to college when they would not have. But she did not have a large impact on their academic work. Margaret's culturally relevant pedagogy influenced these Latinas primarily by developing pride in their home cultures. In school, some of them had been downplaying their background. Margaret helped them see academic success and being Latina as mutually compatible. Thus these girls accomplished two central goals of culturally relevant pedagogy-to succeed academically, by mainstream standards, and to develop pride in their home cultures-but Margaret herself deserves credit only for the latter result.

With the boys, most of whom did not do well in school, Margaret also succeeded in developing their pride in being Latino. These boys had been proud of their Mexican heritage before Margaret's arrival, but she brought official sanction to this pride. By valuing their home culture and by teaching them some of the accomplishments of Latino peoples, Margaret helped these boys resist the devaluation of their language and culture that too often occurs in mainstream US society. Despite her efforts, however, these boys did not succeed academically. Most came to see the school as less hostile, but most continued to fail one or several courses, and most have by now dropped out of high school. These boys could not reconcile their aspirations as rural, working class Mexican men-to be the head of their own household, to work hard at physical labor and support a family, to remain close to their own extended family-with the expectations of the school that they will "better" themselves and move beyond their culture. 
So Margaret's culturally relevant pedagogy accomplished one of its goals for both groups of Latino students-to develop pride in their home cultures. The significance of this accomplishment became clear in the academic year following Margaret's departure, when the ESL room reverted to a more traditional style. The room is now used almost exclusively for formal instruction. Whereas before there might have been eight students in and out of the room during a period, now there are no more than three. Student activities are much more spatially segregated, with staff using a table in an adjoining room for students working on unrelated projects. There is no longer student work on the walls, and there is also a new clock.

Students who were formerly successful in school are doing about as well as before. These students, however, report that "everyone misses Margaret." Even though current staff are effective instructors, these students miss the support and camaraderie of the old room. Tellingly, students no longer know much about what other Latinos in the school are doing. When asked how some other Latino student is doing, people often report that they "haven't seen him." Losing Margaret has been more difficult for the less academically successful English-speaking students. These students no longer go to the ESL room. Current staff have good intentions, but because they are perceived as less supportive many students will not give them a chance.

\section{Conclusions}

Clearly something was lost when Margaret left Havertown High. But we argue that the situation is not simple. Margaret's culturally relevant pedagogy helped in some respects, but it did not help all the Latino students both succeed academically and develop pride in their home cultures. It may be that, with more power and institutional support, Margaret could have 
implemented her pedagogy more widely across the school and thereby could have helped more of the Latino students succeed academically. But we argue that Margaret also ran into the deep conflict between rural Mexican and mainstream US values described by Valdés (1996). Valdés describes how mainstream US schooling practices presuppose culturally specific values and assumptions, emphasizing individual accomplishments and the freedom to choose one's own life course. She describes how rural, working class Mexicans value reciprocity and loyalty to the family over individual glory, and how these more collective values lead some Mexicans and Mexican Americans to forego academic successes for the sake of maintaining their connections.

Valdés ends her book on what seems a painful note. She argues that we should not define "success" as only individual academic success. People like the Latino males in Havertown may be perfectly successful, by their standards, if they drop out of high school and remain loyal, contributing members of their families. Valdés argues, further, that we should not wipe out this alternative value system through well-intentioned efforts to help Latino students "succeed" by mainstream standards. We are left with a hard choice: to encourage the male Latino adolescents in Havertown to pursue academic success, as defined by the school, would seem to undermine their own cultural values; but to encourage them to reject mainstream schooling will close off many opportunities that they may not at this point fully understand.

Our description of Margaret’s culturally relevant pedagogy has also shown, however, that educators do not always face this hard choice. The Latina adolescents did not encounter an either-or choice between home and host cultures, and they benefited from Margaret’s culturally relevant pedagogy. Because of their different adaptive strategies, Latino and Latina adolescents reacted differently to Margaret’s educational strategy. Sometimes the differences between 
minority and mainstream US cultural values force minority students and their teachers to make hard choices. But sometimes minority students and their teachers can, through culturally relevant pedagogy, manage both academic success and cultural celebration. 


\section{Notes}

*We would like to thank the National Academy of Education and the Spencer Foundation for supporting this research through a grant to the first author. We would like to acknowledge the insight and work of our research assistants, Levania Davis and Gerardo Joven, whose help has been indispensable. We would also like to thank Pablo Chavajay, Norma González, Enrique Murillo, Genevieve Patthey-Chavez, Barbara Rogoff, Carlos Vélez-Ibáñez, and Ana Celia Zentella for suggestions and comments.

${ }^{1}$ All names and many identifying details have been changed.

${ }^{2}$ Margaret's own ethnic identity is hybrid. She was born a New England Anglo, not far from Havertown, but she considers herself partly Latina. She lived for several years in Colombia, where she met her husband, and she has four children. She once remarked that, when she was pregnant with these children and exchanging blood with them, she herself became physically part Latina. Her pride in Latino cultures, and her ability to speak Spanish, were important to many of her students.

\section{References}

Azmitia, M., Cooper, C., García, E. \& Dunbar, N. (1996). The ecology of family guidance in low-income Mexican-American and European-American families. Social Development, $\underline{5}, 1-23$. 
Freeman, R. (1996). Dual-language planning at Oyster Bilingual School. TESOL Quarterly, 30, 557-582.

Gallimore, R. \& Goldenberg, C. (1993). Activity settings of early literacy. In E. Forman, N. Minick, C. Stone (Eds.), Contexts for learning (pp. 315-335). NY: Oxford University.

Griffith, D. \& Kissam, E. (1995). Working poor. Philadelphia: Temple University.

Irvine, J. (1990). Black students and school failure. NY: Greenwood.

Ogbu, J. (1987). Variability in minority school performance. Anthropology \& Education

Quarterly, 18, 312-334.

Rogoff, B. (1991). Apprenticeship in thinking. NY: Oxford University.

Rogoff, B., Mistry, J., Göncü, A. \& Mosier, C. (1993). Guided participation in cultural activity by toddlers and caregivers. Monographs of the Society for Research in Child Development (Serial No. 236), Volume 58, Number 8.

Rothenberg, B. (1995). Understanding and working with parents and children from rural Mexico. Menlo Park, CA: The CHC Center for Child and Family Development.

Stull, D., Broadway, M., \& Erickson, K. (1992). The price of a good steak. In L. Lamphere (Ed.), Structuring diversity (pp.35-64). Chicago: University of Chicago.

Suárez-Orozco, C. \& Suárez-Orozco, M. (1995). Transformations. Stanford, CA: Stanford University.

Valdés, G. (1996). Con respeto. NY: Teachers College.

Vásquez, O., Pease-Alvarez, L., \& Shannon, S. (1994). Pushing boundaries. NY: Cambridge University.

Vélez-Ibáñez, C. (1993). Ritual cycles of exchange. In P. Frese (Ed.), Celebrations of identity: 
multiple voices in American ritual performance. Westport: Bergin \& Garvey.

Vélez-Ibáñez, C. (1996). Border visions. Tucson: University of Arizona.

Wortham, S. (2001). Gender and school success in the Latino diaspora. In S. Wortham, E.

Murillo \& E. Hamann (Eds.), Education, Policy, and the Politics of Identity in the New

Latino Diaspora. Westport, CT: Ablex. 